\title{
DESAFÍOS Y ESPERANZAS \\ DE LA PASTORAL VOCACIONAL EN LA POSTMODERNIDAD
}

DOI: https://doi.org/10.52039/seminarios.v51i178.686

Autor: Alexis Rodríguez Vargas. Secretario Ejecutivo de la Comisión Nacional de Seminarios y Vocaciones (CONASEV) de Costa Rica.
Dios dialoga con el ser humano en cada contexto histórico, también en la post-modernidad. Entender la crisis como peligro-oportunidad y tener confianza en Dios que hace todo nuevo y cala en la nueva cultura, nos tiene que mover a encontrarnos abiertos, a la escucha.

Hacia el año 626 a. C. (año 13 del Rey Josías de Judá), un joven residente en los alrededores de Jerusalén se siente llamado por Dios. Posteriormente esta experiencia es puesta por escrito del siguiente modo:

Entonces me fue dirigida la Palabra de Yahvé en estos términos: Antes de formarte en el vientre te conocí, antes que salieras del seno materno te consagré; te constituí profeta de las naciones. niño".

Yo dije: “¡Ah Señor Yahvé! Mira que no sé hablar, que soy un

Y me dijo Yahvé: no digas «soy un niño» porque irás adonde yo te envíe, y todo lo que mande dirás. No les tengas miedo, que yo estoy contigo para librarte -oráculo de Yahvé-. Entonces alargó Yahvé su mano, tocó mi boca y me dijo: "mira pongo mis palabras en tu boca. Desde hoy mismo te doy autoridad sobre naciones y reinos para arrancar y arrasar, para destruir y derribar, para edificar y plantar" (Jr 1,4-10). 
Este conocido texto leído en clave vocacional, ha servido como inspiración para muchos jóvenes que a lo largo de los siglos han tratado de responder al llamado del Señor; por tanto, al reflexionar sobre la pastoral vocacional en un nuevo contexto cultural, resulta adecuado tomarlo como punto de partida. El presente artículo pretende dar una mirada sinóptica al fenómeno postmoderno y a los desafíos y esperanzas que podrían surgir en este contexto para la pastoral vocacional, partiendo de la convicción de que Dios sigue llamando a toda persona a conocerlo y amarlo.

La vocación de Jeremías, resumida en estas pocas líneas, refleja algunos de los temores e inseguridades de un joven cualquiera ante la misión que sobrepasa su capacidad. Parecería que a inicios del siglo XXI, ante el llamado universal del Señor, aún se pueden dar estos sentimientos, sobre todo porque también hoy la vocación de cada cristiano está relacionada con esta actitud de derribar y de edificar. El punto de partida es que Dios dialoga con el ser humano en cada contexto histórico y la postmodernidad no es la excepción. Ya se decía que lo que no es asumido no es redimido; por lo tanto para hacer la propuesta redentora del Evangelio en esta nueva época de la historia habrá que intentar conocerla y lograr que las semillas del Reino presentes en toda cultura, crezcan y den una cosecha abundante.

\section{I. ¿Qué se entiende por postmodernidad?}

Escapa al alcance de este escrito ofrecer una visión exhaustiva del fenómeno postmoderno, pero sí resulta necesario proponer algunos de los elementos que lo caracterizan, buscando encontrar así un lenguaje común con los lectores.

En primer lugar la postmodernidad es parte del proceso histórico, no es algo que ha sucedido sino más bien algo que el ser humano ha propiciado; además, no es un punto único en el que se pueda ubicar a todo el género humano, pues se nota que en la actualidad coexisten diversas formas culturales en lugares geográficamente muy cercanos: América Latina es un buen ejemplo de lo anterior. En otras palabras, no se entiende la postmodernidad como la única expresión cultural sino como una manifestación con características concretas que coexiste con otros modelos diversos.

Jean-Francois Lyotard (2001) afirma que la modernidad no es una época, sino más bien un modo (es el origen latino de la palabra) en el 
pensamiento, en la enunciación, en la sensibilidad (p. 35). Es un modo de entender el mundo y el puesto del ser humano en el cosmos a partir de los llamados mega-relatos. La postmodernidad plantea una crítica a dicha narrativa y busca nuevos modos de ser. Para entender este proceso resulta conveniente echar un vistazo a las principales etapas de historia en occidente. Albert Borgmann (1993) ofrece al respecto una síntesis muy ilustrativa que sirve como cimiento para este recorrido.

Los primeros siglos de la era cristiana contemplaron en occidente el cenit y ocaso del imperio romano y la subsiguiente época de dominio bárbaro. A partir del siglo IX, con el reinado de Carlomagno se integran tres elementos que dan a luz la llamada Edad Media: la cultura y conocimiento de la antigüedad clásica, el orden feudal de tradición germana y la visión espiritual de la tradición cristiana. El mundo medieval al igual que todas las culturas premodernas; estaba limitado a espacios reducidos, centrado en el cosmos y cohesionado por la divinidad (Borgmann, 1993, p. 22).

Este orden fue destrozado por los aportes de Colón, Copérnico y Lutero. Con el descubrimiento del nuevo mundo Colón amplió los límites geográficos del universo conocido, por su parte Copérnico destruyó el geocentrismo del modelo ptolomeico y lo substituyó por el heliocentrismo, y finalmente la reforma luterana, con su precepto de sola Sacra Scriptura, hizo al creyente la autoridad final de la fe cristiana y debilitó el poder de Dios, presente en la comunidad.

Pocos años después surgen los fundadores del orden moderno, a quienes Borgmann sintetiza en tres autores y sus respectivas obras, a saber: Francis Bacon (Nueva Atlántida, 1627), René Descartes (El discurso del método, 1637) y John Locke (Segundo tratado sobre el gobierno civil, 1690).

La obra de Bacon propone el dominio de la naturaleza a través de la investigación y la tecnología, la de Descartes señala el método que propiciará un nuevo orden y la de Locke indica las implicaciones sociales de este nuevo proyecto. En síntesis: podemos pensar en la modernidad como la integración de los proyectos de Bacon, Descartes y Locke; como la fusión de dominar la naturaleza con la primacía del método y la soberanía de lo individual (Borgmann, 1993, p. 25).

Gracias a los avances técnicos y científicos, el modelo surgido de la síntesis de estos autores gozó de buena salud y prácticamente rigió el mundo hasta bien entrado el siglo XX, pero actualmente como afirma Carlos Rojas: 
"Hemos llegado a un punto en que ya no existen meta-relatos. Los meta-relatos son a las sociedades modernas, lo que los mitos a las sociedades tradicionales. Los meta-relatos son discursos totalizadores en los que los miembros de una sociedad encuentran legitimación y justificación de las instituciones sociales, económicas y políticas" (Rojas Osorio, 2003, p. 16)

Ya en la segunda mitad del siglo pasado, el proyecto moderno entró en crisis, pero aún hoy no termina de consolidarse la propuesta postmoderna. El padre Cristian Precht afirma:

"Cada vez hay mayor consenso en que hemos pasado de una época de cambios a un cambio de época. Y un cambio epocal, o la inauguración de una nueva era de la humanidad, lleva largo tiempo en su gestación. De ahí que tenemos la impresión de vivir en tiempos de parto, en que algo nuevo está por nacer, aunque todavía no veamos con claridad las características más propias de su ser" (1996, p. 9).

En vista de lo anterior es notable que todavía no hay consenso en qué se debe entender por postmodernidad, no en vano Lyotard sostiene que bajo la palabra postmodernidad pueden encontrarse agrupadas las perspectivas más opuestas (2001, p. 41). Sin embargo, Frederic Jameson (2001) propone una sistematización que resulta útil, textualmente afirma:

"a grandes rasgos cabe destacar cuatro posturas generales con respecto a la postmodernidad entre las muchas declaraciones recientes sobre el tema; pero incluso este esquema relativamente pulcro o combinatoire, se complica porque da la impresión de que a cada una de estas posibilidades se les puede asignar una expresión o bien políticamente progresista o bien políticamente reaccionaria" (2001, pp. 85-86).

La primera postura es anti-moderna, por ejemplo en Tom Wolfe y su obra ¿Quién teme al Bahaus feroz? En ella se encuentra el odio apasionado a lo moderno que rezuma sarcasmo (Jameson, 2001, p. 86).

Como contraposición a la anterior se encuentra otra postura promoderna, que mira con recelo la postmodernidad mediante la reafirmación del auténtico impulso de una tradición modernista que sigue considerando viva y dinámica (Jameson, 2001, p. 87). Entre estos autores se ubican Hilton Kramer, Jürgen Habermas y el mismo Lyotard.

Lyotard entre otras cosas cree que esta explosión de formas postmodernistas va a hacer volver el modernismo, sobre todo porque la disolu- 
ción de los valores personales, el anonimato y demás son en su opinión berrinches anti-modernistas, un invento de la burguesía que trata de adaptarse a los cambios sociales.

En tercer lugar aparecen los pro-postmodernistas como Jenkins, y finalmente los anti-postmodernistas como Manfred Tapuri. A este respecto otros postmodernos interesantes son Giger, Tarantino, Moore, Eco, Fowles.

En vista de lo anterior, definir qué se entiende por postmodernidad es difícil, en este sentido Borgmann (1993) afirma que

"la postmodernidad es un movimiento amplio y colorido ... utilizo el término para marcar la división emergente entre dos épocas. Entre los autores de quienes he aprendido a reconocer este canal, algunos recibirían con agrado la etiqueta de postmodernos para sus trabajos mientras otros se sentirían ofendidos por el mismo. Lo realmente importante para mis propósitos es que ellos han iluminado el fin de una era y el inicio de otra (p. 48).

Así, se puede sintetizar la dificultad de definir la postmodernidad a partir de los siguientes elementos:

- No representa una crítica madura frente a la modernidad.

- Es todavía una posición ambigua.

- Puede describirse como una crítica y reacción en progreso.

- Otros la entienden como una fase de autocrítica de la modernidad frente a sus propias acciones.

En vez de buscar una definición de la postmodernidad podría resultar más conveniente ubicar algunos de sus rasgos más sobresalientes, entre éstos se ubican los siguientes:

- Ve en la situación actual (modernidad) un agotamiento de la razón y un callejón sin salida. Jesús Andrés Vela (1994) hace una triple crítica a la modernidad a saber: la absolutización de la razón, la ausencia de felicidad y la relativización de todo.

- Critica los paradigmas modernos: el positivismo, el utilitarismo que destruye la ecología, la razón instrumental.

- Plantea nuevos paradigmas.

Con respecto a este último punto, dichos paradigmas no son un producto final, ni aceptado universalmente, pero entre otros se pueden indicar los siguientes: 
- No es posible conocer la realidad, ésta es una mera construcción inestable

- La razón no es más que una argumentación del deseo y del poder.

- Lo universal es un invento relativo convertido en absoluto, por tanto no existen ni ley natural ni ley positiva.

- El individuo es un sujeto fragmentario sostenido por el flujo a su alrededor.

- El relativismo es absoluto ¡Todo es relativo! (Paradójicamente lo único absoluto es la opinión individual).

Los elementos citados tienen diversas expresiones, entre ellas cabe señalar: el gusto por el morbo, la degradación social e individual, la violencia, pero sobre todo lo lúdico que resulta siempre y que lo hace más cercano a la experiencia de clase social. De todas maneras ningún postmoderno sabe lo que hace, dice o critica, al fin y al cabo todos y nadie somos postmodernistas.

La cultura postmoderna se manifiesta en los campos más variados, a modo de ejemplo se pueden considerar los siguientes:

1. A nivel económico salta a la vista una lectura marcada por situaciones conflictivas: desempleo y subempleo, la integración de mercados, la globalización, la brecha creciente entre los ricos y los pobres y otros más.

2. Desde el punto de vista social la configuración actual es un caleidoscopio inmenso de doctrinas, estilos de vida, lugares de encuentro, nociones de familia, formas de sexualidad, etc.

3. En lo referente a la política se replantean las formas de gobierno, presentándose gran desencanto con los partidos tradicionales, al mismo tiempo los grupos minoritarios hacen oír su voz con más intensidad.

4. El fenómeno de la comunicación social trasciende la mera transmisión de información y plantea una forma de vivir vicariamente mediante la identificación con las imágenes, los astros del cine, los deportistas, los guiones de televisión.

5. Ronald Inglehart (1991), plantea el surgimiento de una nueva ética de valores postmodernistas que transforman orientaciones religiosas, costumbres sexuales y normas culturales, esta transformación toca aspectos tan variados como la ecología, la espiritualidad, el valor de la vida animal, etc. 
6. Además lo individual y lo social se mezclan y se invierten, se intenta compensar la intervención pública (que permite observar en vivo desde una guerra hasta una autopsia) con una defensa a ultranza de lo privado como espacio de ocio y de consumo.

7. Finalmente, en el campo religioso también se puede encontrar diversas posiciones. Por un lado se plantea un evidente descenso en la práctica religiosa tradicional y una búsqueda de nuevas manifestaciones del fenómeno religioso.

Al respecto Inglehart (1991) afirma:

"el aparente declive de las normas tradicionales religiosas y sociales tiende a ir ligado al cambio de valores materialistas hacia otros postmaterialistas y ambos procesos parecen ser componentes de un amplio cambio cultural que caracteriza la transición de una sociedad industrial a otra post-industrial. El giro hacia el postmodernismo y el declive de las formas tradicionales de religión van unidos en alguna medida, porque comparten una causa común: los niveles de seguridad personal sin precedentes que provienen de los lazos económicos de la postguerra y el surgimiento del Estado de bienestar. No obstante, el post-materialismo y la secularización son dos dimensiones diferentes influenciadas hasta cierto punto por factores causales distintos" (p. 224).

En lo referente al secularismo Chadwick et alii sostienen que existe una triple dimensión: la primera se refiere a la autonomía de instituciones sociales tales como la política, la educación y la familia respecto de la institución religiosa (por ejemplo la prohibición a rezar en las escuelas públicas, el aumento de relaciones sexuales prematrimoniales, la prohibición de distintivos religiosos, etc).

La siguiente dimensión se refiere a los temas mundanos asumidos por grupos religiosos tradicionales frente a preocupaciones por el otro mundo, (luchas contra la pobreza y el racismo, o la protección del ambiente).

La última dimensión se refiere a la aceptación individual de las creencias religiosas tradicionales y a la participación en actividades religiosas, la influencia de la religión disminuye cuando las necesidades emocionales y sociales de los miembros de la sociedad se ven satisfechos por otras instituciones sociales, por tanto la vivencia religiosa se limita al ámbito privado del sujeto.

Pese al declive de las manifestaciones tradicionales de religiosidad, en muchos ambientes se da un retorno a lo sagrado; según Rodrigo Díez 
(1995), en la actualidad hay diversas vías de acceso al Trascendente, entre ellas cita:

- La vía estética: la admiración por el arte provoca una epifanía, la naturaleza posee un carácter numinoso y la deidad se oculta tras la idea de lo bello.

- La vía ética: permanece en muchos ambientes la idea de que la divinidad propicia el consenso social contra la anarquía.

- La vía mística: la vivencia profunda, lo existencial y no la racionalización de la fe, propician el encuentro con la divinidad.

$\mathrm{Al}$ concluir esta primera sección se evidencia la entrañable maraña que se cobija bajo el término de postmodernidad, tal vez esto nos permita ver bajo una nueva luz el número 12 del documento conclusivo del Primer Congreso Continental Latinoamericano de Vocaciones (documento de Itaici, 1994):

La cultura post-moderna, con sus aspectos contradictorios y cuestionadores, causa un fuerte impacto en el hombre y la mujer de hoy, sobre todo en los jóvenes. Si por un lado, ella ayuda a rescatar el valor de la subjetividad y de la individualidad, la importancia de la afectividad y de la sexualidad humana, la ética de la vida, la búsqueda de la felicidad y de la realización personal, por el otro, ha generado un fuerte relativismo y subjetivismo, acompañado de una mentalidad pragmática y hedonista, con serias consecuencias en el campo de los valores cristianos. Las familias enfrentan serios problemas de estabilidad y muchas veces se desintegran. Los jóvenes se manifiestan más inestables, inseguros y con dificultades para asumir compromisos definitivos.

\section{Pastoral Vocacional}

$\mathrm{Al}$ entrar a considerar los retos y desafíos que la postmodernidad plantea a la pastoral vocacional conviene retomar algunos elementos centrales a esta tarea de la Iglesia, no con el fin de profundizar en el tema sino para contextualizar el concepto.

Según el documento de Itaici 26: La pastoral vocacional se entiende como el servicio a cada persona a fin de que ella pueda descubrir el camino para la realización de un proyecto de vida tal como lo quiere Dios y como lo necesita el mundo de hoy. Por su parte PDV 34 dice que la pas- 
toral vocacional es la encargada de cuidar el nacimiento, el discernimiento y el acompañamiento de las vocaciones.

El documento final del congreso europeo de vocaciones (1997) en su número 26 plantea algunos principios generales de la pastoral vocacional que no se pueden dejar de enunciar:

- La pastoral vocacional es la perspectiva originaria de la pastoral.

- La pastoral vocacional es gradual y convergente.

- La pastoral vocacional es general y específica.

- La pastoral vocacional es universal y permanente.

- La pastoral vocacional es personalizada y comunitaria.

- La pastoral vocacional es la perspectiva unitaria y sintética de la pastoral.

Este mismo documento a partir del $\mathrm{N}^{\mathrm{o}} 32$ presenta el proceso pedagógico de la vocación con los siguientes pasos: sembrar, acompañar, educar, formar y discernir.

\section{Desafíos y esperanzas}

Es frecuente encontrar en ciertos ambientes alusiones a la crisis de la Iglesia, esta crisis también toca a la Pastoral Vocacional; precisamente por esto es muy importante aclarar que esta sección no sigue el esquema tradicional de luces y sombras que la pastoral vocacional podría enfrentar a la postmodernidad. La luz y la sombra se excluyen mutuamente, pero los desafíos y las esperanzas, ocurren simultáneamente. Un autor afirma que el término chino de crisis (weiji) se compone de dos caracteres que significan peligro y oportunidad ocurriendo al mismo tiempo (Slaikeu, 1988, p.12), y en el Nuevo Testamento "crisis" es un momento privilegiado de discernimiento. Desde esta perspectiva cabe enfocar la crisis vocacional ante la postmodernidad ante todo desde una óptica de confianza, y se proponen una serie de puntos que sirvan más para fomentar la discusión que para ofrecer conclusiones.

\section{El reto de dejar la impronta cristiana en la postmodernidad}

La postmodernidad no es un fenómeno concluso sino un mundo en gestación, como cristianos tenemos el desafío de ayudar a dar a luz este 
nuevo mundo. Sería insuficiente recordar las raíces cristianas de occidente si no podemos calar la nueva cultura con la buena noticia. Esto implica una actitud de diálogo (hablar y escuchar), hemos dicho hasta la saciedad que la fe no se impone sino que se propone.

En este diálogo habrá que considerar que aspectos fundamentales de la fe se han transmitido en categorías modernas que van pasando y como traducirlas en otros moldes, pero además habrá que considerar cómo establecer el diálogo, no desde una actitud de simetría donde la voz de la Iglesia es la autoridad, actitud que responde mas bien a un modelo de cristiandad, sino más bien desde la complementariedad en la que esta voz es una entre otras (ser más compañeros que maestros).

Al respecto del diálogo Rodrigo Díez (1995), plantea que es importante el respeto por la pluralidad y la apertura, recuperar la estética, lo experiencial, lo imaginativo, lo lúdico, lo festivo y lo corporal, además de retomar el valor de lo cotidiano.

El respeto que propicia el diálogo se apoya en valores de la postmodernidad tales como la crítica a la razón como absoluto, el ser humano percibido de un modo más integral, el rechazo al progreso técnico-científico y económico como camino a la felicidad, la ecología como lugar de encuentro con el trascendente. Mirar estos elementos permite que la realidad hable al creyente y teniendo un espíritu contemplativo se abre la posibilidad de que al compartir un espacio y un tiempo común con sus implicaciones concretas, éste pueda entenderse con los que piensan distinto haciendo un esfuerzo solidario. Una posición de rigidez sólo dificultará el diálogo.

\section{El reto de mantener la vocación eclesial}

Otro reto tiene que ver con la toma de conciencia sobre la propia identidad como Iglesia a inicios del nuevo milenio. ¿A qué está llamando Dios hoy a su pueblo? Sólo desde el encuentro con Jesucristo vivo se puede dar respuesta a este interrogante. Aspectos como la oración, la vida comunitaria, la pastoral integrada e integral, la inculturación del Evangelio a las circunstancias históricas concretas, el deseo de incidir positivamente en el mundo actual con una propuesta significativa, el reconocimiento humilde de los errores y aciertos, son elementos que legitiman el mensaje cristiano hoy día. 
La pastoral vocacional no podrá ser mediadora en el diálogo entre la libertad perfecta de Dios y la libertad imperfecta del ser humano postmoderno, si no contempla con respeto absoluto tanto al Verbo encarnado en la historia como al sagrario de la conciencia humana.

\section{El reto de creer que Dios todo lo hace nuevo}

Un tercer elemento tiene que ver con la capacidad de mantener la utopía. Ante una visión en la que según Lyotard (2001), el mega-relato ha perdido legitimidad, es necesario enfrentar la tentación del desánimo, del abatimiento, de la patología del cansancio, de la desesperación. El cristiano afirma que otro mundo es posible, y que ese mundo es un ya, pero todavía no. Éste se configura en los micro-relatos de angustias y esperanzas de cada hombre y mujer a quien Dios ha llamado a la vida.

Dialogar con la postmodernidad no implica claudicar en las convicciones más profundas, porque como dice el autor de la carta a los Hebreos: Cristo es el mismo ayer, hoy y siempre.

\section{El reto de vivir la propia vocación}

Siendo los mismos animadores de la pastoral vocacional, hijos de la postmodernidad, con todas sus contradicciones, reciben un llamado especial a la coherencia que dé credibilidad a su mensaje. Ante la sociedad que sobrevalora la imagen, la vocación de ser iconos de la Trinidad se intensifica. El mensaje del Señor hoy no será narrativa sino imagen, imagen que en ocasiones podrá vestirse de nuevas formas. En vista de esto, la capacidad de adaptarse, de cambiar, de proponer y atender, de mantener lo esencial y no lo accidental, son desafíos fundamentales.

El camino de la pastoral vocacional en la postmodernidad tendrá que pasar por el ser humano, por cada individuo que tome conciencia de la propia responsabilidad activa en la vida personal y social, al fin y al cabo todo persona es vocacionada.

\section{El reto de mirar el mundo con ojos de fe}

Sin querer pecar de ingenuo en este último punto, se puede sostener que pese a que algunos ambientes de la cultura postmoderna descalifican 
el mensaje de Jesucristo y rechazan su divinidad, la Iglesia no podrá asumir ni una actitud defensiva (ya terminó la etapa apologista) ni derrotista. No hay por qué pensar que la era cristiana ha terminado. Sí se puede modificar el estilo en que se vive el cristianismo, pero la vocación a ser sal de la tierra y luz del mundo sigue siendo válida hoy como ayer.

Si el joven Jeremías afrontó las complejas circunstancias de su existencia con temor, y a pesar del deseo de abandonar su llamado, siguió adelante, como lo atestigua al afirmar: Yo decía: "No volveré a recordarlo, ni hablaré más en su Nombre". Pero había en mi corazón algo así como un fuego ardiente, prendido en mis huesos, y aunque trabajaba por ahogarlo, no podía. (Jr 20,9), es evidente que hoy también es válido sentir temor, inseguridad o dificultades para el compromiso total, pero que las palabras del Señor a su profeta en la antigüiedad, resuenen en los oídos de la Iglesia de hoy y la animen en su vocación para que el fuego tampoco se apague en la postmodernidad: Que ellos se vuelvan a ti, y no tú a ellos...pues contigo estoy Yo.*

* Bibliografía citada por el autor:

- Biblia de Jerusalén. (1975) Desclee de Brouwer, Bilbao.

- Borgmann, Albert (1993) Crossing the postmodern divide, The university of Chicago Press, Chicago.

- Chadwick, Bruce A. et al (1995) Tendencia de la religión y la secularización en Langlois, Simon y de Campo, Salustiano (Eds) ¿Convergencia o divergencia? Comparación de tendencias sociales recientes en las sociedades industriales, pp 221-271. Ed. Fundación BBV, Bilbao.

- Diez, Rodrigo (1995) La experiencia religiosa en la postmodernidad en Mayéutica № $21 \mathrm{pp}$. 161-190, Madrid.

- Inglehart, Ronald (1991) El cambio cultural en las sociedades industrialmente avanzadas. Siglo XXI de España editores S.A., Madrid

- Jameson, Frederick (2001) Teoría de la postmodernidad. Tercera edición, Trotta S.A., Madrid.

- Juan Pablo II (1992) Pastores dabo vobis. Ed. Vaticana, Vaticano.

- Lyotard, Jean-Francois (2000) La condición postmoderna, $7^{a}$ edición, Ed. Cátedra, Madrid.

- Lyotard, Jean-Francois (2001) La postmodernidad explicada a los niños, Sexta reimpresión, Ed. Gedisa, S.A.

- Obra pontificia para las vocaciones eclesiásticas (1997), Nuevas vocaciones para una nueva Europa. Ed. Vaticana, Vaticano.

- Precht, Cristian (1996) Gestar un mundo nuevo. Unión Gráfica Ltda., Bogotá.

- Primer congreso continental de vocaciones (1994), La pastoral Vocacional en el continente de la esperanza. CELAM, Bogotá.

- Rojas Osorio, Carlos (2003) La filosofía en el debate postmoderno. Ed. Universidad Nacional, Heredia.

- Slaikeu, Karl (1998) Intervención en crisis. Ed. Manual Moderno, México.

- Vela, Jesús Andrés (1994). La postmodernidad en Cursos de Iglesia y Vocación. № 177, Casa de la Juventud, Bogotá. 